\title{
Comparison between two districts of the effects of an air pollution intervention on bronchial responsiveness in primary school children in Hong Kong
}

\author{
C M Wong, T H Lam, J Peters, A J Hedley, S G Ong, A Y C Tam, J Liu, D J Spiegelhalter
}

Department of

Community Medicine, The University of

Hong Kong, Patrick

Manson Building

South Wing, 7 Sassoon

Road, Hong Kong

C M Wong

T H Lam

J Peters

A J Hedley

S G Ong

J Liu

Room 1106, Melbourne

Plaza, 33 Queen's

Road, Central, Hong

Kong

A Y C Tam

Biostatistics Unit, Medical Research Council, University

Forvie Site,

Cambridge

D J Spiegelhalter

Correspondence to:

Professor Hedley.

Accepted for publication 9 March 1998

\begin{abstract}
Study objective-This study examined the impact on children's respiratory health of a government air quality intervention that restricted the sulphur content of fuels to $0.5 \%$ from July 1990 onwards.

Design/setting/participants-This study examined the changes, one and two years after the introduction of the intervention, in airway hyperreactivity of nonasthmatic and non-wheezing, primary 4, 5 , and 6, school children aged 9-12 years living in a polluted district compared with those in a less polluted district. Bronchial hyperreactivity (BHR) (a 20\% decrease in FEV $_{1}$ provoked by a cumulative dose of histamine less than $7.8 \mu \mathrm{mol}$ ) and bronchial reactivity slope (BR slope) (percentage change in logarithmic scale in FEV per unit dose of histamine) were used to estimate responses to a histamine challenge. The between districts differences after the intervention were studied to assess the effectiveness of the intervention.
\end{abstract}

Main results-In cohorts, comparing measurements made before the intervention and one year afterwards, both BHR and BR slope declined from $29 \%$ to $16 \%$ $(p=0.026)$ and from 48 to $39(p=0.075)$ respectively in the polluted district; and from $21 \%$ to $10 \%(p=0.001)$ and 42 to 36 $(p>0.100)$ in the less polluted district. Comparing measurements made in 1991 (one year after intervention) with those in 1992 (two years after intervention), only the polluted district showed a significant decline from $28 \%$ to $12 \%(p=0.016)$ and from 46 to $35(p=0.014)$, for BHR and BR slope respectively, with a greater decline in both responses $(p=0.018$ and 0.073$)$ than in the less polluted district.

Conclusion-Bronchial hyperresponsiveness tests can be used to support the evaluation of an air quality intervention. The demonstrated reduction in bronchial hyperresponsiveness is an indication of the effectiveness of the intervention.

(F Epidemiol Community Health 1998;52:571-578)

Air pollution is a major and increasing health hazard in rapidly expanding urban areas in the Asia Pacific rim. In 1989, Kwai Tsing district was one of the most air polluted areas in Hong Kong with about 8000 industrial outlets ${ }^{1}$ (giv- ing rise to multiple point sources of air pollution) and a residential population of 441000 (8\% of the total Hong Kong population $)^{2}$ living mostly in high rise, low cost housing. Southern district (population 257 000), with a similar type of housing to that of Kwai Tsing was mainly residential. A respiratory health study, carried out over a two year period in 1989 and 1990 with surveys using self completed questionnaires, showed an excess of respiratory symptoms (sore throat, cough, wheeze, and phlegm) in primary school children in Kwai Tsing compared with those in Southern district, which had better air quality, ${ }^{3}$ although there were no differences in $\mathrm{FEV}_{1}$ and FVC measured by spirometry between the two districts. ${ }^{4}$ To provide an objective indicator of any adverse health effect resulting from air pollution, in 1990 a histamine challenge test was carried out in April to May on a sub-sample of the children. A higher prevalence of bronchial responsiveness was found in those children living in the more polluted district. ${ }^{5}$ This finding suggested that urban pollutants could induce bronchial constriction as well as increase the likelihood of a bronchial constriction response to allergens in both healthy and asthmatic subjects.

In Australia bronchial hyperresponsiveness has been found in infants after they inhaled low concentrations of histamine and it was postulated that this was an inborn characteristic that would be lost as they grew older, depending on individual genetic or environmental factors. ${ }^{7}$ Exposure to low concentrations of sulphur dioxide $\left(\mathrm{SO}_{2}\right)$ during infancy has also been related to bronchial hyperresponsiveness in schoolchildren $7-13$ years of age. ${ }^{8}$

In July 1990, new Government fuel regulations were implemented that restricted the sulphur content of fuels to $0.5 \% .^{9} \mathrm{SO}_{2}$ levels measured in Hong Kong Government Environmental Protection Department air monitoring stations fell rapidly by $84 \%$ in Kwai Tsing district whereas those in Southern district remained stable (fig 1). ${ }^{10-12}$ A greater reduction in $\mathrm{SO}_{2}$ level was observed in Kwai Tsing district as expected because there were more factories there than in the Southern district and the fuel regulation affected the sulphur contents of fuel used by factories. There were smaller reductions in total (TSP) and respirable suspended particulates (RSP) $(<10 \mu \mathrm{m})$ of $23 \%$ and $18 \%$ respectively. During the period of the fieldwork in April and May of each year, $\mathrm{SO}_{2}$ concentrations in Kwai Tsing fell from 

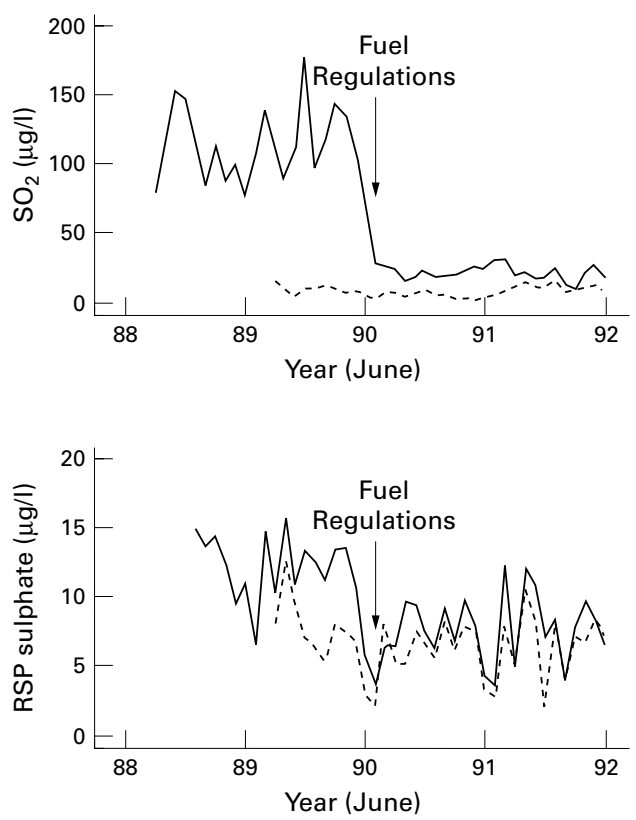

Figure 1 Trends in air pollution as shown by levels of sulphur dioxide $\left(\mathrm{SO}_{2}\right)$ and sulphates in respirable particulates (SO RSP) at monitoring stations in Kwai Tsing (solid line) and in Southern (dotted line) districts measured by the Hong Kong Environmental Protection Department 1988-92, before and after the introduction of regulations restricting the sulphur content of fuels.

$124.5 \mu \mathrm{g} / \mathrm{m}^{3}$ (1990) to $24.5 \mu \mathrm{g} / \mathrm{m}^{3}$ (1991) and $25.0 \mu \mathrm{g} / \mathrm{m}^{3}$ (1992); in Southern the levels were lower and stable and averaged $7.7 \mu \mathrm{g} / \mathrm{m}^{3}$ (range $2-13)$. The fall in sulphate in respirable particulates ranged from $38 \%$ in Kwai Tsing to $25 \%$ in Southern (fig 1). Nitrogen dioxide levels remained unchanged. ${ }^{10}$ After the introduction and implementation of the fuel regulations there was a greater decline in the polluted compared with the less polluted district for reported symptoms of cough or sore throat, phlegm and wheezing. ${ }^{13}$

This study, using the histamine challenge test, examined the between district differences for changes in bronchial responsiveness in children aged 8-11 years living and attending schools in a more polluted district, compared with those from a district with better air quality, before and after the implementation of the fuel regulations.

\section{Methods}

STUDY DESIGN, SCHOOLS, AND SUBJECTS

Because the fuel regulations were implemented across the Territory, it was not feasible to use an experimental design to study the effect of this intervention on respiratory health. A before and after design was used in two districts: Kwai Tsing, which showed a reduction in pollutant levels after the intervention, and for comparison, Southern district, with lower stable air pollutant levels both before and after the intervention.

Details of the first year of the respiratory health study in 1989 and the 1990 baseline study on bronchial responsiveness have been reported elsewhere. ${ }^{3-5}$ In 198911 schools, five in Kwai Tsing and six in Southern were selected and all primary 3 and 4 students (age
8 to 10 years) were included. Selection was based on the assessment of school sites that were considered by local district board officials and the Environmental Protection Department to be representative of the air quality in each of the two districts.

In 1990, before the fuel intervention, a subset of four schools, two in each district, was chosen in which to perform histamine challenge tests. One class was randomly selected from each of primary 4 and primary 5 , in both morning and afternoon sessions, in each of the four schools. All 522 children on the school register were asked, through their parents, to participate and 423 were eventually measured. In 1991, the same children measured in 1990 (now primary 5 and 6 students) were remeasured. In addition, a new class of primary 4 children was recruited from each of the same four schools. Of the 721 children invited, 20\% refused and 573 were measured. In 1992, the 1991 primary 4 and 5 children who had become primary 5 and 6 were re-measured and a new class of primary 4 was added, from each of the four schools. This resulted in measurement of a sample of 524 children and a refusal rate of $15 \%$. The 1990 primary 5 children, who had become primary 6 in 1991, could not be followed up in 1992 because they had completed their primary education and moved on to secondary schools elsewhere (fig 2).

The study design had two parts. Part 1 comprised a descriptive (cross sectional) study, in two districts, of all primary 4-5 children in each of the three years as follows. (Primary 6 children were not included for the sake of comparability and some children participated in more than one year) (fig 2). (a) 1990:preintervention year, primary 4 and 5 children; (b) 1991: one year after intervention, primary 4 (new), and primary 5 (first measured in 1990 as primary 4); (c)1992:two years after intervention, primary 4 (new), and primary 5 (first measured in 1991 as primary 4).

Part 2 is a comparison between districts of three cohorts of children. (The most polluted district, Kwai Tsing, was regarded as the index group; and the less polluted district, Southern, was the control group) (fig 2). (a) 1990-91 cohort, to show the effect one year after the intervention; (b) 1991-92 cohort, to show the late effect two years after the intervention; and (c) 1990-92 cohort, to show the changes in histamine challenge test responses in three successive years.

Written consent to participate in the histamine challenge test was obtained from the child's parent or guardian. Ethical approval for the study was obtained from the Ethics Committee of the Medical Faculty of the University of Hong Kong. Children with a history of either asthma medication use or wheezing on the day of test were not included in the histamine challenge test. To have a homogeneous group of well subjects, children who reported ever having asthmatic and/or wheezing symptoms ( $8 \%$ in Southern and $11 \%$ in Kwai Tsing on average over the three years) were also excluded from the study. 

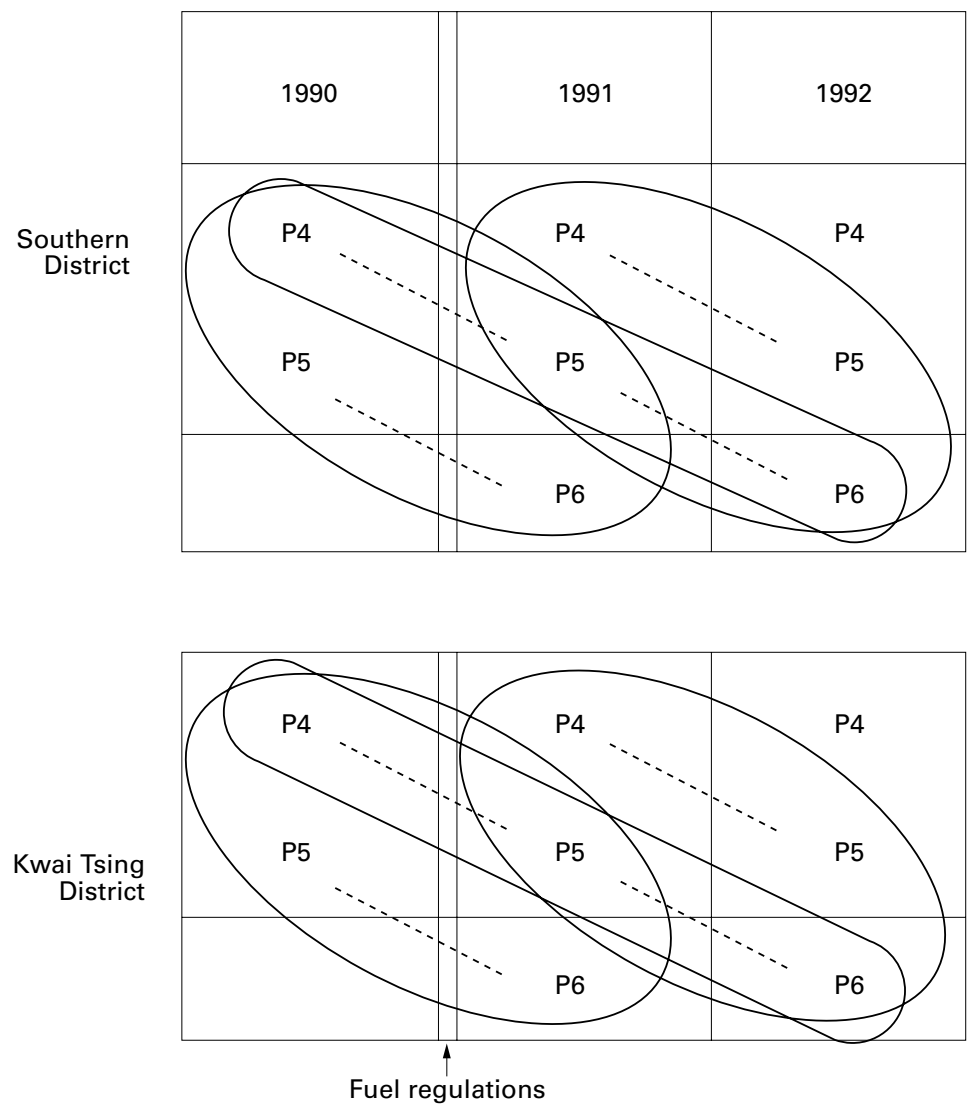

Figure 2 Study design and classes of primary school children by year and grade. Double line indicates the introduction of the fuel regulations. Part 1: Cross sectional comparison of primary classes over three years 1990 (primary 4 and 5), 1991 (primary 4 and 5), and 1992 (primary 4 and 5) shown in the columns. Part 2: Analysis of three cohorts 1990-91, 1991-92, and 1990-1992 is shown in the diagonal enclosures. Cohorts are indicated by broken lines.

\section{QUESTIONNAIRES}

Students completed a structured questionnaire, developed after reference to the Medical Research Council Questionnaire on Respiratory Symptoms and other internationally recognised standard questionnaires, ${ }^{14-16}$ in class under the supervision of a trained field worker. No teachers were present. The questionnaire asked for information on the children's respiratory symptoms, their smoking behaviour, exposure to smoking at home, and demographic factors including sex, age, and place of birth. Parents also completed a questionnaire, which was brought home by the children and returned to the school when completed in a sealed envelope. The parent's questionnaire asked for information on respiratory symptoms and common respiratory diseases in both children and parents, type of housing, type of domestic fuel, use of incense and mosquito coils, parents' education levels, occupation and smoking history, and details on others smoking in the family home.

PHYSICAL EXAMINATION

The children had their heights and weights measured using standard methods. ${ }^{17}$ Children with a current upper respiratory tract infection or a history of one in the previous 10 days, and those with a history of either asthma medica- tion use or wheezing on the day of examination were excluded from the histamine challenge test.

\section{HISTAMINE CHALLENGE TEST}

The histamine challenge test was carried out in a designated room in each school using the method of Yan et al. ${ }^{18}$ Before administration of the test, the output of the nebullisers was checked and the subject's ventilatory function was measured using a portable dry wedged spirometer (Vitalograph). Children with a forced expiratory volume in one second $\left(\mathrm{FEV}_{1}\right)$ of less than $60 \%$ of expected were to be excluded but none was eventually excluded by this criterion. The challenge test was carried out for, at most, nine histamine doses (starting dose saline, second dose $0.03 \mu \mathrm{mol}$ and systematically doubled for each subsequent dose) up to the end dose (cumulative 7.8 $\mu \mathrm{mol})$. The test was terminated at $7.8 \mu \mathrm{mol}$ or at an earlier dose in all cases where there was a $20 \%$ drop of $\mathrm{FEV}_{1}$ from the baseline.

\section{OUTCOME VARIABLES}

Two outcome variables for bronchial responsiveness were calculated from the results of the histamine challenge test.

(1) Bronchial hyperreactivity (BHR): a dichotomous variable, based on observation of the cumulative dose of histamine that provoked a $20 \%$ decrease $\left(\mathrm{PD}_{20}\right)$ in $\mathrm{FEV}_{1}$. BHR was considered to be present if $\mathrm{PD}_{20}<7.8 \mu \mathrm{mol}$ and absent if $\mathrm{PD}_{20} \geqslant 7.8 \mu \mathrm{mol}^{19}$

(2) Bronchial reactivity (BR) slope: a continuous variable defined as the percentage change (logarithmic scale) in $\mathrm{FEV}_{1}$ from the first to last dose per cumulative dose of histamine. Higher positive values indicate a more adverse reaction. ${ }^{19}$

\section{STATISTICAL ANALYSIS}

\section{Descriptive study}

Descriptive statistics with adjustment for age for the two outcome variables were obtained for each sex separately and also for all children adjusted for sex and age. The outcome variables were compared by districts for each of the three years of the study.

Age and sex were adjusted by the method of direct standardisation using the age by sex distribution for all primary 4 and 5 children for the three years as standard. Other potential confounding variables and any learning effect that might be acquired in performing the test repeatedly are referred to in the analysis of the follow up cohort.

\section{Cohort study}

Crude prevalence rates for $\mathrm{BHR}$ and mean responses for BR with $95 \%$ confidence intervals were derived for each of two district cohorts in each year of measurement.

The changes in the responses between calendar years of measurement, that is (a) the second year (1991) compared with the first (1990); (b) 1992 compared with 1991; and (c) the second year (1991) and the third year (1992) compared with the first year (1990), were examined within each district cohort 
using statistical modelling based on generalised estimating equations (GEE) procedure, ${ }^{20}$ with adjustment for correlation between repeated measurements and for the six characteristics listed: sex (boys compared with girls); age (at the first year of measurement); years of examination (dummy variables for 1991 and 1992 compared with the baseline year); school session (afternoon compared with morning sessions); father's education level (regarded as a continuous variable and coded as $0,1,2,3$ and 4 for no formal education, primary, lower secondary, upper and post secondary education respectively); number of categories of smokers in the family home (one, two or more compared with none with categories defined as mother, father, sibling and others, such as grandparents or lodgers); $\mathrm{FEV}_{1}$ (regarded as a continuous variable).

The variables selected for the adjustment were similar to those in our previous studies..$^{513}$

The changes were then compared between cohorts in the two districts to investigate if there were greater changes in the district that had a greater improvement in air quality. Greater changes in terms of improvement in bronchial responsiveness would provide supportive evidence that the intervention was effective. Logistic regression and multiple regression, with adjustment for correlation between years of measurements using the unstructured working correlation assumption in the GEE procedure, were performed for $\mathrm{BHR}$ and BR slope by a sub-routine ${ }^{21}$ in the statistical package S-Plus. GEE is considered the best method for analysis of longitudinal data and is more robust to occurrence of any imbalance in numbers between different levels of the independent variables, than by other multivariate methods, such as multivariate analysis of variance method. All significance tests were two sided.

For analysis on data for the two districts together a district variable (Kwai Tsing compared with Southern) and a district by year interaction variable (defined as the crossproduct of the calendar year and district variables) were created and included in the modelling. If the intervention was effective we would expect the changes in Kwai Tsing to be greater than those in Southern as only the former had a marked improvement in air quality after the intervention.

Any learning effect from repeated tests and aging effect per year was expected to affect the cohorts in the two districts by a similar amount so that a comparison of the effect between any two years and across the two districts would not be biased.

Finally all the three cohorts (represented by broken lines in fig 2) were modelled simultaneously. Dummy variables that defined the three cohorts; age at 1990; and period variables for 1991 and 1992 with 1990 as reference; 1991 and 1992 year by district interaction variables together with the potential confounding factors including the six characteristics, as defined in the previous analyses, were included in same model.

The prevalence of current smoking in our sample of children was similar in both districts, and on average three children $(0.5 \%)$ were current smokers (smoked more than one cigarette per week). No additional adjustment was made for this in the modelling.

Table 1 Histamine challenge results for non-asthmatic and non-wheezing primary 4 and 5 children by age and by district

\begin{tabular}{|c|c|c|c|c|c|c|c|c|}
\hline & & & \multicolumn{6}{|c|}{ Year of measurement } \\
\hline & & & \multicolumn{2}{|l|}{1990} & \multicolumn{2}{|l|}{1991} & \multicolumn{2}{|l|}{1992} \\
\hline \multicolumn{3}{|c|}{ (a) $\operatorname{BHR}(95 \% \mathrm{CI})$ : } & \multicolumn{2}{|l|}{$\%$} & \multicolumn{2}{|l|}{$\%$} & \multicolumn{2}{|l|}{$\%$} \\
\hline \multirow[t]{4}{*}{ Girls } & $<10.6 \mathrm{y}:$ & $\mathrm{S}$ & 30.0 & $(17.3,42.7)$ & 15.0 & $(3.9,26.1)$ & 3.5 & $(-1.3,8.3)$ \\
\hline & & $\mathrm{KT}$ & 18.2 & $(6.8,29.6)$ & 28.2 & $(14.1,42.3)$ & 13.5 & $(4.2,22.7)$ \\
\hline & $\geqslant 10.6 \mathrm{y}:$ & $\mathrm{s}$ & 18.2 & $(8.0,28.4)$ & 9.1 & $(-0.7,18.9)$ & 11.8 & $(0.9,22.6)$ \\
\hline & & KT & 22.0 & $(9.3,34.6)$ & 19.4 & $(6.5,32.4)$ & 9.5 & $(-3.0,22.1)$ \\
\hline \multirow[t]{4}{*}{ Boys } & $<10.6 \mathrm{y}:$ & $\mathrm{S}$ & 20.8 & $(9.3,32.3)$ & 24.4 & $(11.9,37.0)$ & 5.9 & $(-2.0,13.8)$ \\
\hline & & $\mathrm{KT}$ & 38.1 & $(23.4,52.8)$ & 26.7 & $(13.7,39.6)$ & 8.1 & $(-0.7,16.9)$ \\
\hline & $\geqslant 10.6 \mathrm{y}:$ & $\mathrm{S}$ & 20.3 & $(10.1,30.6)$ & 14.3 & $(5.6,22.9)$ & 21.7 & $(11.2,32.1)$ \\
\hline & & $\mathrm{KT}$ & 31.4 & $(18.6,44.1)$ & 21.9 & $(7.6,36.2)$ & 16.7 & $(1.8,31.6)$ \\
\hline \multirow{2}{*}{\multicolumn{2}{|c|}{ Standardised ${ }^{\star}$ : }} & $\mathrm{S}$ & 22.6 & $(16.9,28.3)$ & 15.8 & $(10.5,21.1)$ & 10.9 & $(6.5,15.2)$ \\
\hline & & KT & 27.4 & $(21.0,33.9)$ & 24.2 & $(17.3,31.1)$ & 12.2 & $(6.3,18.1)$ \\
\hline \multicolumn{3}{|c|}{ (b) Mean BR slope $(95 \% \mathrm{CI})$ : } & $10^{-2}$ & & $10^{-2}$ & & $10^{-2}$ & \\
\hline \multirow[t]{4}{*}{ Girls } & $<10.6 \mathrm{y}:$ & $S$ & 40.1 & $(32.6,47.7)$ & 32.0 & $(22.0,42.0)$ & 23.6 & $(17.7,29.4)$ \\
\hline & & $\mathrm{KT}$ & 49.8 & $(39.5,60.2)$ & 45.5 & $(35.9,55.1)$ & 31.1 & $(23.4,38.8)$ \\
\hline & $\geqslant 10.6 \mathrm{y}:$ & $S$ & 44.7 & $(34.4,55.1)$ & 33.3 & $(24.1,42.4)$ & 35.7 & $(18.9,52.5)$ \\
\hline & & KT & 37.9 & $(28.7,47.2)$ & 44.9 & $(31.2,58.6)$ & 34.5 & $(22.6,46.4)$ \\
\hline \multirow[t]{4}{*}{ Boys } & $<10.6$ y: & $\mathrm{S}$ & 44.6 & $(37.4,51.7)$ & 49.6 & $(39.3,60.0)$ & 32.1 & $(24.5,39.7)$ \\
\hline & & $\mathrm{KT}$ & 50.7 & $(42.8,58.7)$ & 46.5 & $(38.3,54.8)$ & 41.1 & $(32.5,49.7)$ \\
\hline & $\geqslant 10.6 \mathrm{y}:$ & $\mathrm{S}$ & 39.3 & $(33.4,45.3)$ & 40.9 & $(33.7,48.1)$ & 39.8 & $(31.5,48.1)$ \\
\hline & & $\mathrm{KT}$ & 52.4 & $(41.8,63.0)$ & 42.1 & $(30.9,53.3)$ & 38.0 & $(28.7,47.3)$ \\
\hline \multirow{2}{*}{\multicolumn{2}{|c|}{ Standardised ${ }^{\star}$ : }} & $\mathrm{S}$ & 42.0 & $(38.1,45.8)$ & 39.0 & $(34.3,43.6)$ & 32.7 & $(27.8,37.6)$ \\
\hline & & $\mathrm{KT}$ & 48.3 & $(43.4,53.1)$ & 44.7 & $(39.3,50.0)$ & 36.1 & $(31.5,40.8)$ \\
\hline \multicolumn{9}{|c|}{ (c) Sample size } \\
\hline \multirow[t]{4}{*}{ Girls } & $<10.6 \mathrm{y}:$ & $\mathrm{S}$ & 50 & & 40 & & 57 & \\
\hline & & KT & 44 & & 39 & & 52 & \\
\hline & $\geqslant 10.6 \mathrm{y}:$ & $\mathrm{s}$ & 55 & & 33 & & 34 & \\
\hline & & KT & 41 & & 36 & & 21 & \\
\hline \multirow[t]{4}{*}{ Boys } & $<10.6 \mathrm{y}:$ & $\mathrm{S}$ & 48 & & 45 & & 34 & \\
\hline & & $\mathrm{KT}$ & 42 & & 45 & & 37 & \\
\hline & $\geqslant 10.6 \mathrm{y}:$ & $\mathrm{S}$ & 59 & & 63 & & 60 & \\
\hline & & KT & 51 & & 32 & & 24 & \\
\hline
\end{tabular}

$\mathrm{BHR}=$ Bronchial hyperreactive response (that is $\mathrm{PD}_{20}<7.8 \mu \mathrm{mol}$ ); $\mathrm{BR}$ slope $=$ bronchial response slope; $\mathrm{S}=\mathrm{Southern} ; \mathrm{KT}=\mathrm{Kwai}$ Tsing. ${ }^{*}$ The standard was a $2 \times 2$ sex by age (young or older than 10.6 years) distribution for the total number of observations in the three years for both districts $(n=1042)$. 
Table 2 Histamine challenge results for non-asthmatic and non-wheezing primary school children in cohorts measured in years 1990 (primary 4/5)-1991 (5/6); 1991 (4/5)-1992 (5/6), and 1990 (4)-1991 (5)-1992 (6)

\begin{tabular}{|c|c|c|c|c|c|c|c|}
\hline & \multicolumn{7}{|c|}{ Years of measurement (primary classes) } \\
\hline & $1990(4 / 5)$ & $1991(5 / 6)$ & $1991(4 / 5)$ & $1992(5 / 6)$ & 1990 (4) & $1991(5)$ & $1992(6)$ \\
\hline (a) $\mathrm{BHR}(95 \% \mathrm{CI})$ & $\%$ & $\%$ & $\%$ & $\%$ & $\%$ & $\%$ & $\%$ \\
\hline Southern & $21.1(14.9,27.2)$ & $9.7(5.2,14.2)$ & $14.1(8.6,19.6)$ & $13.1(7.9,18.4)$ & $22.7(13.2,32.1)$ & $11.1(3.9,18.4)$ & $12.0(4.6,19.4)$ \\
\hline Kwai Tsing & $28.9(21.6,36.1)$ & $15.7(9.9,21.4)$ & $27.9(19.3,36.5)$ & $11.8(5.5,18.0)$ & $30.6(17.7,43.5)$ & $17.8(6.6,28.9)$ & $10.9(1.9,19.9)$ \\
\hline (b) BR slope $(95 \% \mathrm{CI})$ & $10^{-2}$ & $10^{-2}$ & $10^{-2}$ & $10^{-2}$ & $10^{-2}$ & $10^{-2}$ & $10^{-2}$ \\
\hline Southern & $42.2(37.7,46.7)$ & $36.4(31.6,41.2)$ & $37.6(32.7,42.5)$ & $35.4(30.6,40.3)$ & $41.7(36.6,46.9)$ & $37.9(31.7,44.2)$ & $35.5(30.0,41.0)$ \\
\hline Kwai Tsing & $48.2(43.1,53.2)$ & $39.0(33.8,44.3)$ & $45.7(39.2,52.1)$ & $35.2(30.8,39.7)$ & $52.8(43.2,62.4)$ & $41.0(31.2,50.7)$ & $34.6(28.6,40.6)$ \\
\hline \multicolumn{8}{|l|}{ (c) Sample size } \\
\hline Southern & 171 & 165 & 156 & 160 & 75 & 72 & 75 \\
\hline Kwai Tsing & 149 & 153 & 104 & 102 & 49 & 45 & 46 \\
\hline
\end{tabular}

Abbreviations as shown in table 1.

\section{Results}

The following results were obtained from the sample with all asthmatics and wheezers excluded.

\section{DESCRIPTIVE STUDY}

Table 1 shows the prevalence of BHR and the mean value of BR slope with $95 \%$ confidence intervals (95\% CI) for non-asthmatic and nonwheezy children in the two districts over three years by sex and age group before and after standardisation according to the sex by age distribution for all the subjects in the three years. From 1990 to 1992, in both districts, consistent trends of decreasing bronchial responsiveness were seen in the standardised rates or means, with the children in Kwai Tsing tended to be more responsive than those in the Southern district.

COHORT STUDY

Table 2 shows the crude prevalence with $95 \%$ CI in the years 1990-91, 1991-92, and the 1990-92 for cohorts in the Southern and Kwai Tsing districts respectively.

\section{0-91 (primary 4/5-5/6) cohorts}

In the year before the intervention (1990), the point estimates of both response variables of the histamine challenge test showed that children (primary 4/5) in Kwai Tsing performed worse than those in Southern.

One year after the intervention (1991) the children (now primary 5/6) in each district showed improvements in both histamine challenge responses compared with the previous year and the observed differences between the two districts became smaller in both challenge test responses.

\section{1-92 (primary 4/5-5/6) cohorts}

For the new primary 4/5 cohort in 1991 (one year after the intervention), children in Southern performed better than those in Kwai Tsing as shown in the point estimates of both histamine challenge responses. However, in 1992 (two years after the intervention) children in Kwai Tsing improved on their performance in both responses over the previous year, to the extent that children in Kwai Tsing showed similar responsiveness as those in Southern.

1990-92 (primary 4-6) cohorts

For the cohorts of children who were followed up and measured successively in all of the three years when they were primary 4,5 , and 6 respectively, the point estimates of both histamine challenge responses showed a decline over the three years in both districts, with the rate of decline in reactivity for children in Kwai Tsing being faster than that for children in Southern.

MODELLING FOR CHANGES AFTER INTERVENTION For estimating the changes between years in histamine challenge responses and the between districts differences in the changes, none of the potential confounding factors were found to be statistically significant except father's educational attainment and $\mathrm{FEV}_{1}$. The changes over years for cohorts within districts and the differences in changes between districts are as follows:

Table 3 Changes in bronchial challenge responses for the non-asthmatic and non-wheezing children between 1990 (before intervention) and 1991 (one year after intervention) for the 1990-91 (primary 4/5-5/6) cohort; between 1991 (one year after intervention) and 1992 (two years after intervention) for the 1991-92 (4/5-5/6) cohort within Southern and Kwai Tsing respectively as well as differences between the two districts, with adjustment for confounding factors *

\begin{tabular}{|c|c|c|c|c|c|c|}
\hline \multirow{3}{*}{$\begin{array}{l}\text { Histamine challenge } \\
\text { response }\end{array}$} & \multicolumn{4}{|l|}{ District } & \multirow{2}{*}{\multicolumn{2}{|c|}{$\begin{array}{l}\text { Differences between } \\
\text { districts in changes over } \\
\text { two yearst }\end{array}$}} \\
\hline & \multicolumn{2}{|l|}{ Southern } & \multicolumn{2}{|l|}{ Kwai Tsing } & & \\
\hline & OR $(95 \% \mathrm{CI})$ & $\mathrm{p}$ value & OR $(95 \% \mathrm{CI})$ & $\mathrm{p}$ value & $\mathrm{z}$ value & $\mathrm{p}$ value \\
\hline 1990 v 1991 & $0.45(0.24,0.83)$ & 0.001 & $0.51(0.28,0.92)$ & 0.026 & 0.422 & \\
\hline $1991 v 1992$ & $\begin{array}{l}1.07(0.56,2.06) \\
10^{-2}\end{array}$ & $\ddagger$ & $\begin{array}{l}0.46(0.24,0.87) \\
10^{-2}\end{array}$ & 0.016 & -2.363 & 0.018 \\
\hline (b) BR slope & Coeff $(95 \%$ CI) & $\mathrm{p}$ value & Coeff $(95 \%$ CI) & $\mathrm{p}$ value & $\mathrm{z}$ value & $\mathrm{p}$ value \\
\hline 1990 v 1991 & $-4.94(-11.33 .1 .45)$ & $\ddagger$ & $-6.23(-13.11,0.65)$ & 0.075 & -0.592 & \\
\hline $1991 v 1992$ & $-2.19(-8.78,4.43)$ & $\neq$ & $-7.92(-14.25,-0.96)$ & 0.014 & -1.790 & 0.073 \\
\hline
\end{tabular}

${ }^{\star}$ Confounding factors in the models include sex (male $v$ female), age in the first year (every year older), session of class (pm $v$ am) education attainment of father (regarded as continuous and code as $0-4$ for not formal, primary, lower secondary, upper secondary, and post-secondary), housing type (public $v$ others), number of smoker categories in family home of child ( 1 and 2 categories $v 0$ ), forced expiratory volume in one second. †Estimated by the district by year interaction term in each model. $\ddagger \mathrm{p}$ Value $>0.100$. OR $=$ Odds ratio, Coef $=$ regression coefficient. Other abbreviations as table 1 . 
Table 4 Changes in bronchial challenge responses for the non-asthmatic and non-wheezing children from 1990 (before intervention) to 1991 (one year after intervention) and to 1992 (two years after intervention) for the 1990-92 (primary 4-6) cohort within Southern and Kwai Tsing respectively as well as differences between the two districts, with adjustment for confounding factors*

\begin{tabular}{|c|c|c|c|c|c|c|c|}
\hline \multirow{2}{*}{\multicolumn{2}{|c|}{$\begin{array}{l}\text { Histamine challenge } \\
\text { response }\end{array}$}} & \multicolumn{4}{|l|}{ District } & \multirow{2}{*}{\multicolumn{2}{|c|}{$\begin{array}{l}\text { Differences between districts } \\
\text { in changes over two yearst }\end{array}$}} \\
\hline & & \multicolumn{2}{|l|}{ Southern } & \multicolumn{2}{|l|}{ Kwai Tsing } & & \\
\hline \multirow{3}{*}{$\begin{array}{l}\text { (a) BHR } \\
1990\end{array}$} & & OR $(95 \% \mathrm{CI})$ & $\mathrm{p}$ value & OR $(95 \% \mathrm{CI})$ & $\mathrm{p}$ value & $\mathrm{z}$ value & $\mathrm{p}$ value \\
\hline & $v 1991$ & $0.41(0.17,0.98)$ & 0.044 & $0.68(0.24,1.95)$ & & 0.594 & $\ddagger$ \\
\hline & $v 1992$ & $\begin{array}{l}0.53 \\
10^{-2}\end{array}(0.17,1.64)$ & $\ddagger$ & $\begin{array}{l}0.37(0.13,1.08) \\
10^{-2}\end{array}$ & 0.070 & -0.675 & $\ddagger$ \\
\hline \multirow{3}{*}{$\begin{array}{l}\text { (b) BR slope } \\
1990\end{array}$} & & Coeff $(95 \% \mathrm{CI})$ & $\mathrm{p}$ value & Coeff $(95 \% \mathrm{CI})$ & $\mathrm{p}$ value & $\mathrm{z}$ value & $\mathrm{p}$ value \\
\hline & $v 1991$ & $-4.14(-11.00,2.72)$ & $\ddagger$ & $-3.09(-13.05,6.87)$ & $\ddagger$ & -0.674 & \\
\hline & $v 1992$ & $-5.45(-14.25,3.35)$ & $\ddagger$ & $-7.89(-15.73,-0.05)$ & 0.048 & -1.909 & 0.056 \\
\hline
\end{tabular}

${ }^{\star}$ Confounding factors in the models include sex (male $v$ female), age in the first year (every year older), session of class (pm $v$ am) education attainment of father (regarded as continuous and code as $0-4$ for not formal, primary, lower secondary, upper secondary, and post-seconary), housing type (public $v$ others), number of smoker categories in family home of child ( 1 and 2 categories $v 0$ ), forced expiratory volume in one second. †Estimated by the district by year interaction term in each model. $\ddagger \mathrm{p}$ Value $>0.100$. Abbreviations as in tables 1 and 3 .

1990-91 (primary 4/5-5/6) cohorts (table 3)

There were decreases (that is, negative changes) in BHR within each of the two districts $(p=0.001$ in Southern; $p=0.026$ in Kwai Tsing), but there were no differences in the decreases between them $(p>0.100)$.

1991-92 (primary 4/5-5/6) cohorts (table 3) There were declining trends in both histamine challenge response measures within Kwai Tsing (BHR $p=0.016 ; B R$ slope $p=0.014$ ) but not in Southern $(p>0.100)$. Between the two districts there were greater decreases in Kwai Tsing in both responses $(\mathrm{p}=0.018$ for BHR; $\mathrm{p}=0.073$ for BR slope).

\section{0-92 (primary 4-6) cohorts (table 4)}

From 1990 (before intervention) to 1991 (one year after intervention) the BHR and BR slope declined (that is, negative changes) to a smaller extent in Kwai Tsing than in Southern but the between district difference was not significant ( $p>0.100$ ). From 1990 to 1992 (two years after intervention) there were declines in Kwai Tsing in both responses $(p=0.070$ for $B H R$; $\mathrm{p}=0.048$ for BR slope) and the decreases were greater in Kwai Tsing than in Southern ( $p>0.100$ for BHR; $p=0.056$ for BR slope).

In an analysis of all the 1990-91 (P5-6), 1990-92 (P4-5-6), and 1991-92 (P4-5) cohorts simultaneously with adjustment for cohort effect there were decreases in BR slope $(p=0.000)$, after two years, which were greater in Kwai Tsing than in Southern $(p=0.086)$ (data not shown).

\section{Discussion}

The analysis of both the cross sectional and cohort data showed that, overall, reductions in bronchial responsiveness occurred after implementation of the fuel regulations, which in turn were associated with a marked reduction in both $\mathrm{SO}_{2}$ and sulphate in RSP levels in Kwai Tsing district. These improvements occurred in children who did not have a previous history of asthma or wheezing.

The results from measurements made two years after the intervention provided the strongest support for the effectiveness of the intervention in terms of reducing levels of bronchial hyperresponsiveness. In the descriptive analysis, the children in the more polluted district, Kwai Tsing, experienced greater declines in both outcome measures and therefore benefited more than those in Southern. A similar response was seen in the 1991-92 cohorts with the children in Kwai Tsing experiencing significantly greater declines in both histamine challenge responses and in the 1990-1992 cohorts a greater decline in BR slope occurred within the more polluted district two years after the intervention. These findings suggest that the adverse effects of sulphur related pollutants on bronchial responsiveness are reversible, but that the improvement may only be measureable at least one year after the air quality intervention.

The observation that, to a lesser extent than in Kwai Tsing, the declines in BHR and BR slope were also found in the less polluted Southern district may be accounted for by a number of residual confoundings such as longitudinal aging effect (cross sectional age effect was adjusted for in the modelling) and a learning effect in that children may have overcome psychological stress and acquired better skill in performing the histamine challenge test. Some additional benefit to the children in Southern District from a general improvement in air quality, which is not necessarily reflected in levels of specific pollutants, also cannot be excluded.

We acknowledged that caution should be exercised when interpreting data obtained from measurements on the same subjects on more than one occasion. In the descriptive analysis, to estimate the histamine challenge responses across the three years using the maximum number of available measurements, observations on the same subjects in two successive years were included. Our conclusions however have been mainly based on analysis of the cohort measurements where adjustment has been made for any correlation arising from repeated measurements.

In the analysis, as we did not have complete addresses and codes for the residence of the subjects, we were not able to take the autocorrelation within districts into account. We acknowledge this may be a limitation of the study. However, there should be no autocorrelation between the two districts as they are far apart and separated from each other by several kilometres of sea and hills (fig 3). 


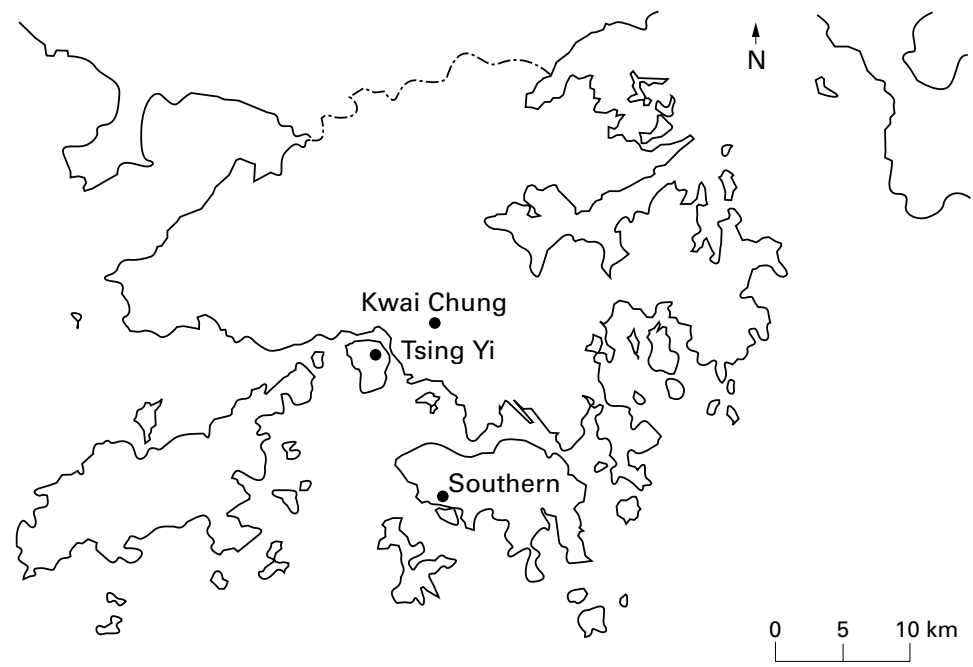

Figure 3 Outline map of Hong Kong with location of Kwai Tsing (Kwai Chung and Tsing Yi) and Southern district.

The respiratory challenge technique has been used in clinical studies of child asthmatics, ${ }^{22}$ atopic children, ${ }^{23}{ }^{24}$ and in surveys of populations of children who are well..$^{25-29}$ However, it has not been used in well populations to measure the health effects of an air quality intervention that resulted in a reduction of ambient air pollutants. The prevalence of BHR in our children living in the less polluted district was similar to that found in other studies ${ }^{25}{ }^{26}$ but for those children living in the area with high pollution, the BHR fell to such levels only after the air quality had improved. The BHR prevalence in both districts was slightly higher than that reported in China ${ }^{28}$ but the children in that study were older.

After implementation of the fuel regulations in Hong Kong, the decline in $\mathrm{SO}_{2}$ was accompanied by a reduction in excess risks for reported respiratory symptoms cough, phlegm, and wheeze in Kwai Tsing compared with Southern District. ${ }^{13}$ Thus these subjective health measures are corroborated by the objective data of the histamine challenge test and taken together the results suggest that this type of air quality intervention can result in measurable gains in the respiratory health of young children.

The health effects of different components of mixed urban air pollution are difficult to define but the current focus is on the effect of fine particulates of less than $10 \mu \mathrm{m}$. Seaton et a ${ }^{30}$ have postulated that ultra fine particulate aerosols cause alveolar inflammation and the release of mediators that provoke acute respiratory illness. Forced vital capacity (FVC) and $\mathrm{FEV}_{1}$ have been shown to improve after an improvement in air quality. ${ }^{31}$ Our findings also suggest that bronchial hyperresponsiveness associated with air pollution, in well populations of children, is reversible after a reduction in levels of air pollutants for one year and, more effectively, for two years after implementation of air quality controls. In this setting the reduction in bronchial hyperresponsiveness followed restrictions in the sulphur content of fuels and, as expected, the major reductions were in $\mathrm{SO}_{2}$ and sulphates in RSP, with smaller but unsustained reductions in total RSP. The observed change in bronchial responsiveness seen in the children in this study is more probably associated with the reduction in fine particulates (fig 1) but the fall in $\mathrm{SO}_{2}$, may also be important if it acts synergistically with particulates to cause adverse respiratory health effects. ${ }^{32-34}$ In this study the observed relations were weak, sometimes below the $5 \%$ significance level, so interpretation of the results should be cautious.

The results from this study, demonstrating a reduction in bronchial responsiveness and respiratory symptoms after an air quality intervention, provide documented evidence of a government intervention to control air quality and can be used by the Government Environmental Protection Department to support an evaluation of the change in regulations. Government policy makers and planners in rapidly developing urban environments in the Asia Pacific region need good quality local data to demonstrate the impact of poor air quality on health. This study shows the feasibility of using tests for bronchial responsiveness in epidemiological surveys to detect apparent subclinical pathophysiological changes in young children and to measure the potential health benefits of interventions designed to improve air quality.

The authors wish to thank the Environmental Protection Department, Hong Kong Government, Kwai Tsing District Board, Glaxo Hong Kong Limited; The Royal Hong Kong Jockey Club and the Mary Sun Medical Scholarship Fund (Hong Kong-Cambridge Link) for their financial support; and all the schools, head teachers, parents and children for their cooperation and participation in the study.

1 Kwai Tsing District Board. Kwai Chung and Tsing Yi District Board Annual Report. Hong Kong: Government Printer, 1988: 8.

2 Census and Statistics Department. Hong Kong 1991 Population Census. 1991. Hong Kong: Government Printer, 1991: 16.

3 Ong SG, Liu J, Wong CM, et al. Studies on the respiratory health of primary school children in urban communities in Hong Kong. Sci Total Environ 1991;106:121-35.

4 Department of Community Medicine, the University of Hong Kong. Air pollution and respiratory health in primary school children in Hong Kong, 1989-1992. A Report to the school children in Hong Kong, 1989-1992. A Report to the Environmental Protection Department, Hong Kong Government. Hong Kong: Department of Commu

5 Tam AYC, Wong CM, Lam TH, et al. Bronchial responsiveness in children exposed to atmospheric pollution in Hong Kong. Chest 1994;106:1056-60.

6 Sheppard D. Sulfur dioxide and asthma - A double-edged sword? F Allergy Clin Immunol 1988;82:961-4.

7 Lesouëf PN, Geelhoed GC, Turner DJ, et al. Response of normal infants to inhaled histamine. Am Rev Respir Dis 1989;139:62-6.

8 Søyseth V, Kongerud J, Haarr D, et al. Relation of exposure to airway irritants in infancy to prevalence of bronchial hyper-responsiveness in schoolchildren. Lancet 1995;345: hyper-respor $217-20$.

9 Hong Kong Government. Air Pollution Control (Fuel Restriction) Regulations 1990. Air Pollution Control Ordinance tion) Regulations 1990. Air Pollution Control Ordinance
(Chapter 311). Gazette 4/1990. Hong Kong: Government

10 Environmental Protection Department. Environment Hong Kong 1991. A review of 1990. Hong Kong: Government Printer, 1991

11 Environmental Protection Department. Environment Hong Kong 1992. A review of 1991. Hong Kong: Government Printer, 1992.

12 Environmental Protection Department. Environment Hong Kong 1993. A review of 1992. Hong Kong: Government Printer, 1993.

13 Peters J, Hedley AJ, Wong CM, et al. Effects of an ambient air pollution intervention and environmental tobacco smoke on children's respiratory health in Hong Kong. Int $\mathcal{f}$ Epidemiol 1996;25:821-8.

14 Medical Research Council. Questionnaire on respiratory symptoms, 1960. London: Medical Research Council, 1960. 15 Fymptoms, 1960. London: Medcal Research Council, 1960. airflow limitation. WHO Regional Publications, European Series No. 12. Copenhagen: WHO, 1982. 
16 Fyfe CE. Influences on the health-related beliefs and behaviours of schoolchildren: implications for health education. [PhD

17 Weiner JS, Lourie JA. Human biology: a guide to field methods. Oxford: Blackwell Scientific, 1969

18 Yan K, Salome CM, Woolcock AJ. Rapid method for measurement of bronchial reactivity. Thorax 1983;38:760-5.

19 Abramson MJ, Saunders NA, Hensley MJ. Analysis of bronchial reactivity in epidemiological studies. Thorax 1990;45 924-9.

20 Liang KY, Zeger SL. Longitudinal data analysis using generalized linear models. Biometrika 1986;73:13-22.

21 Carey VJ. S-Plus library implementation of generalized estimating equations (version 4.3), 1996. (Down loaded from the Statlib archive.)

22 Murray AB, Morrison BJ. The effect of cigarette smoke from the mother on bronchial responsiveness and severity of symptoms in children with asthma. F Allergy Clin Immunol $1986 ; 77: 575-81$.

23 Clough JB, Williams JD, Holgate ST. Effect of atopy on the natural history of symptoms, peak expiratory flow and
bronchial responsiveness in 7-and 8-year old children with cough and wheeze. Am Rev Respir Dis 1991;143:755-60.

24 Murray AB, Morrison BJ. It is children with atopic dermatitis who develop asthma more frequently if the mother smokes. F Allergy Clin Immunol 1990;86:732-9.

25 Salome CM, Peat JK, Britton WJ, et al. Bronchial hyperresponsiveness in two populations of Australian schoolchildren. I. Relation to respiratory symptoms and diagnosed asthma. Clin Allergy 1987;17:271-81.
26 Asher MI, Pattemore PK, Harrison AC, et al. International comparison of the prevalence of asthma symptoms and bronchial hyperresponsiveness. Am Rev Respir Dis 1988; 134:524-9.

27 Martinez FD, Antognoni G, Macri F, et al. Parental smoking enhances bronchial responsiveness in nine-year old children. Am Rev Respir Dis 1988;138:518-23.

28 Zhong NS, Chen RC, O-yang M, et al. Bronchial hyperresponsiveness in young students of southern China: relation to respiratory symptoms, diagnosed asthma, and risk factors. Thorax 1990;45:860-5.

29 Zhong NS, Chen RC, Yang MO, et al. Is asymptomatic Zhong NS, Chen RC, Yang MO, et al. Is asymptomatic
bronchial hyperresponsiveness an indication of potential bronchial hyperresponsiveness an
asthma? Chest 1992;102:1104-9.

30 Seaton A, MacNee W, Donaldson K, et al. Particulate air pollution and acute health effects. Lancet 1995;345:176-8.

31 Arossa W, Spinaci S, Bugiani M. Changes in lung function of children after an air pollution decrease. Arch Environ Health 1987;42:170-4.

32 Ware JH, Ferris BG, Dockery DW, et al. Effects of ambient sulphur oxides and suspended particles on respiratory health of preadolescent children. Am Rev Respir Dis 1986;133:834-42.

33 Dockery DW, Speizer FE, Stram DO, et al. Effects of inhalable particles on respiratory health of children. Am Rev Respir Dis 1989;139:587-94.

34 Jaakkola JJ, Paunio M, Virtinen M, et al. Low-level air pollution and upper respiratory infections in children. $A m \mathcal{F}$ Public Health 1991;81:1060-3. 